\title{
O complexo agroindustrial e a agricultura familiar: além das tradicionais fronteiras ${ }^{1}$
}

The agro-industrial complex and the family based agriculture: beyond the traditional frontiers

\author{
J aqueline Mallmann Haas² \\ Aline Weber Sulzbacher ${ }^{3}$ \\ J airo Alfredo Genz Bolter 4 \\ Pedro Selvino Neumann ${ }^{5}$
}

\begin{abstract}
Resumo: O artigo analisa os principais elementos que contribuíram para a especialização produtiva, especialmente, no âmbito da atividade leiteira do Noroeste do Estado do Rio Grande do Sul, tendo em vista o fomento de uma relação dependente entre empresas processadoras com os produtores de leite. Além disso, propõe-se refletir sobre a ação do extensionista rural e a suposta situação de acomodação da região em torno da integração ao complexo agroindustrial leiteiro. Os procedimentos metodológicos incluíram análise dos referenciais teóricos e pesquisas de campo, com visita a propriedades produtoras de leite, e a análise econômica da sua produção. Dentre os resultados, podese destacar uma dualidade inicial: por um lado, a integração com o complexo agroindustrial garante a manutenção da unidade de produção familiar, mas não sua expansão em longo prazo; por outro lado, ao manter uma renda fixa, não estimula a busca por alternativas diferenciadas capazes de promover autonomia em relação ao sistema. Aliás, a integração também promove a diferenciação horizontal das unidades produtivas com a exclusão daquelas que não atendem as exigências tecnológicas. Estas enfrentam problemas para buscar outras estratégias, uma vez que a produção leiteira é regionalmente difundida, fato que desconsidera outras atividades, principalmente, por parte das instituições ou agentes de extensão públicos.
\end{abstract}

Palavras chaves: agricultura familiar; processamento; leite.

\begin{abstract}
The following article aims to analyze the main elements that contributed to the productive specialization, mostly at the milk activity, in the Northeast Rio Grande do Sul. It was taken in account the maintenance of a dependent relation among processing factories and the milk producers. Besides that, it is proposed a discussion about the action of the large acreage owners and the supposed stagnated situation of the region, towards the integration to the milk agro-industrial complex. The procedures included the analysis of theory references and field researches, and the visitation to milk producer's properties. As results, an initial duality can be pointed: the integration with the agroindustrial complex guarantees the preservation of the family based production unity, although it does not guarantee its long term expansion; on the other hand, by keeping a regular income, it does not stimulate the search for alternatives able to promote autonomy towards the system. The integration also promotes horizontal differentiation of the production unities, by excluding those which do not fulfill the technological demands. These face obstacles looking for other strategies, once the milk production is regionally disseminated, what does not consider other activities, mainly on the behalf of institutions or public extension agents.
\end{abstract}

Key Words: family based agriculture; processing; milk.

JEL: 017.

${ }^{1}$ Artigo recebido em setembro de 2009 e aprovado em agosto de 2010.

2 Doutoranda pelo Programa de Pós-Graduação em Extensão Rural, Departamento de Educação Agrícola e Extensão Rural, Centro de Ciências Rurais da UFSM. Integrante do grupo de pesquisa "Sociedade, Ambiente e Desenvolvimento Rural". Bolsista da CAPES. E-mail: jaquelinehaas@yahoo.com.br

${ }^{3}$ Geógrafa e Mestre em Extensão Rural pela UFSM. Doutoranda em Geografia pela FCT/UNESP. Email: sulzba@hotmail.com

4 Mestre em Desenvolvimento pela UNIJUI. Doutorando no Programa de Pós Graduação em Desenvolvimento Rural - PGDR, na Universidade Federal do Rio Grande do Sul - UFRGS. E-mail: jairobolter13@yahoo.com.br

${ }_{5}$ Doutor em Engenharia de Produção, Professor do Centro de Ciências Rurais, Departamento de Educação Agrícola e Extensão Rural da UFSM. E-mail: neumannsp@yahoo.com.br 


\section{Introdução}

A pecuária leiteira vem se apresentando como uma alternativa para a agricultura familiar, não só no estado do Rio Grande do Sul, mas também no Brasil. Sendo assim fruto de intensos investimentos que têm contribuído até mesmo para a mudança da matriz produtiva de algumas regiões. Nessa situação encontra-se o Noroeste Gaúcho, conhecido tradicionalmente pela produção de grãos, porém essa região vem alterando sistematicamente sua matriz produtiva, sendo hoje baseada fundamentalmente na produção de leite.

A inserção da atividade leiteira, em especial, nas propriedades familiares, decorre do fato que ela apresenta determinadas particularidades, como a alta demanda de mão-de-obra disponível e a garantia de renda mensal dos agricultores (BOLTER, 2009).

No Brasil, em vista de estimular e desenvolver a agricultura familiar se consolidam cada vez mais os Complexos Agroindustriais (CAI). Estes estão presentes, no espaço brasileiro, desde a década de 1980, enquanto uma estratégia estimulada pelas políticas desenvolvimentistas para promover a modernização da agricultura. Neste processo, solidifica-se a cadeia de produção-distribuição-consumo, integrando a indústria processadora com a agricultura numa relação vertical e horizontal (MÜLLER, 1989).

Diante deste contexto, movimenta-se todo um circuito de produtos, que vai desde os insumos (equipamentos e matrizes) até o processamento e comercialização. Na região em estudo, Noroeste Gaúcho, esse processo introduziu os complexos agroindustriais como alternativa de comercialização para a produção leiteira ${ }^{6}$ e, em muitos casos, o fornecimento de crédito para a aquisição de insumos, a fim de qualificar e aumentar a escala de produção.

Atualmente, atentando, em especial, à porção Noroeste do Rio Grande do Sul/ Brasil, o CAI continua exercendo um papel estratégico, principalmente, quanto à compra de matéria-prima das unidades de produção familiar, pagando por isso, aparentemente, um preço coerente com os custos de produção. Integrar-se ao CAI leiteiro vem sendo uma estratégia historicamente difundida, desde 1984, e continua a exercer significativa importância para o conjunto de agricultores familiares e para a região como um todo, principalmente, frente a uma construção política dessa estratégia (HAAS, 2008).

Entretanto, se a estratégia do CAI contribui, por um lado, para a inserção de alguns agricultores familiares, por outro lado também exclui um significativo contingente. Ao definir padrões de produção, essa estratégia desfavorece aqueles com características produtivas relacionadas à baixa escala de produção, ou a distância das unidades produtivas em relação à sede coletora da matéria-prima. Para esses agricultores, essas políticas - preocupadas com o padrão regional - não oferecem alternativas.

Outro contraponto que se pode estabelecer refere-se à acomodação, à integração ao complexo, que pela sua aparente viabilidade econômica para as unidades de produção familiar, parece incitar o agricultor (e o poder local) à acomodação, não buscando outras estratégias que poderiam se apresentar viáveis na

\footnotetext{
${ }^{6}$ Compra direta do agricultor e, no caso das parcerias, desconto em folha para os insumos adquiridos no crédito.
} 
região, como a consolidação de atividades de processamento de leite descentralizadas e autônomas, a partir de Sistemas Agroalimentares Localizados (SIALes).

Os SIALes constituíram-se, inicialmente, como modelos teóricos, mas que vem sendo utilizados como ferramenta para planejar, fortalecer e dar competitividade às concentrações de agroindústrias rurais (BOUCHER, 2000). Compreende-se um SIAL como um sistema que incorpora atividades agroalimentares ligadas a um território (fatores naturais e de construção social e técnica) e a organizações de produção e de serviço associadas mediante suas características e seu funcionamento em um território específico (GÓMEZ; BOUCHER; REQUIER-DESJ ARDINS, 2006). Nos SIALes, a agroindustrialização familiar passa a ser concebida como um meio para reforçar o controle do agricultor sobre a criação de valor agregado na cadeia de produção, o que permitiria aumentar seu nível de ingresso (REQUIERDESJ ARDINS, 1999).

No entanto, este processo de agroindustrialização familiar, que poderia assumir uma conotação emancipatória, apresenta uma série de fatores limitantes, especialmente, quando nos referimos à região Noroeste do Estado do Rio Grande do Sul. Dentre esses fatores, está a possível acomodação dos agricultores familiares, dos agentes de extensão rural e dos próprios representantes políticos frente à consolidação de Complexos Agroindustriais. Estes CAIs, com demandas por diferentes produtos (suínos, leite, soja), oferecem aos agricultores familiares algumas opções de comercialização, contribuindo para um processo de acomodação dos sujeitos rurais, marcado pela desmotivação empresarial, falta de aspiração e, principalmente, subordinação aos preços atribuídos pela indústria. Esse fato parece similar ao analisado por Galbraith (1979), onde povos de diferentes países e regiões acomodaram-se a diferentes níveis de vida - diferentes níveis de pobreza e de prosperidade.

Tomando por base este cenário, tem-se por objetivo analisar os principais elementos que contribuem para a especialização produtiva no Noroeste do Estado do Rio Grande do Sul, bem como as estratégias que as empresas processadoras vêm utilizando para manter sua rede de captação de leite e a dependência dos produtores frente à disputa regional pelo produto. Para tanto, caracteriza-se os produtores de leite do município de Roque Gonzales/RS como um caso representativo da Região Noroeste, levantando-se alternativas e potenciais de agregação de valor para aqueles que estão excluídos das redes dos complexos agroindustriais.

Em outra dimensão, busca-se também identificar as principais motivações que mantém os agricultores integrados e os sintomas da sua possível acomodação. Além disso, propõe-se refletir sobre a ação do extensionista rural frente a esta realidade e a suposta situação de acomodação da região em torno da integração ao complexo agroindustrial (CAI) leiteiro.

\section{Metodologia}

Para elaboração do presente trabalho, utilizou-se como referência a metodologia de Análise e Diagnóstico de Sistemas Agrários, em especial, no tocante aos procedimentos para análise econômica das propriedades familiares. Além disso, outros elementos foram considerados, como: (a) o desenvolvimento da análise e estudo do tema/ objeto de forma progressiva, partindo do geral para o particular; (b) a busca por explicações dos fenômenos e fatos através do uso sistemático do enfoque histórico e da avaliação econômica da atividade agropecuária; (c) utilização da 
estratificação (identificação de tipologias) como procedimento analítico; (d) a análise da realidade em termos sistêmicos, considerando suas inter-relações, em especial, da forma de uso do espaço e as condições agroecológicas (DEFUMIER, 2007).

Portanto, para atender aos objetivos propostos, buscou-se construir um panorama de inserção da problemática (tanto CAIs com questão da produção leiteira) a partir da releitura de referenciais bibliográficos. Em sequência, realizaram-se visitas e entrevistas nas propriedades que se dedicam à produção leiteira no município a fim de aplicar entrevistas para construir uma análise econômica.

De acordo com a abordagem dos Sistemas Agrários, a análise econômica da unidade de produção parte do pressuposto de que a Renda Agrícola (RA) anual obtida pelo produtor e sua família deve ser calculada subtraindo-se do valor agregado os juros, os impostos, a renda da terra e a remuneração da mão-de-obra assalariada, conforme descrito a seguir:

$$
\mathrm{RA}=\mathrm{VA}-\mathrm{J}-\mathrm{S}-\mathrm{T}-\mathrm{I}
$$

Onde: $\mathrm{RA}=$ renda agrícola; $\mathrm{VA}=$ valor agregado; $\mathrm{J}=$ juros pagos aos agentes financeiros; $\mathrm{S}=$ salários pagos aos trabalhadores contratados; $\mathrm{T}=$ arrendamentos pagos aos proprietários da terra; I =impostos e taxas pagas ao Estado.

Para fazer a avaliação econômica, seguindo os pressupostos de Defumier (2007), foi definido, como Nível de Reprodução Social (NRS), o valor de R\$ 5.395,00/ano por unidade de trabalho familiar. Esse valor definido, em janeiro de 2008 (época em que foram efetuados os cálculos), corresponde a treze salários mínimos (incluindo o 13으), o que é considerado como custo de oportunidade deste tipo de mão de obra no mercado de trabalho regional, ou seja, valor que o trabalhador estaria recebendo se empregado fora da propriedade.

Esta análise pressupõe que, quando o sistema de produção praticado não gera um nível de remuneração do trabalho familiar no mínimo equivalente ao seu custo de oportunidade, os agricultores tendem a não acumular fundos suficientes para a reposição dos equipamentos, culminando com a sua exclusão do processo produtivo.

\section{A Relação Entre a Agricultura Familiar e o Complexo Agroindustrial}

No Brasil, a década de 1960 pode ser considerada como um marco temporal, a partir da qual se intensifica o processo de modernização da agricultura. Umas das iniciativas pioneiras das políticas públicas nacionais foi através da promoção da conhecida Revolução Verde, que tinha por intuito incorporar os países pobres na trilha da alta e eficiente produção agropecuária (MONTENEGRO GÓMEZ, 2006). Este processo contribuiu significativamente para a expansão do capitalismo, no espaço rural, e se construiu a partir de um discurso pautado na necessidade de levar ao campo a modernidade:

Escolas, moradias, infra-estruturas de transporte ou eletricidade se somavam à tarefa de disponibilizar um amplo pacote tecnológico de variedades de sementes e insumos, na perspectiva de aumentar a produção e salvar da pobreza, do atraso, da fome, dos costumes selvagens e do desespero as populações excluídas dos países em vias de desenvolvimento que poderiam desemborcar em instabilidade social (MONTENEGRO GÓMEZ, 2006, p. 03). 
Nesse viés, percebe-se uma grande mudança tecnológica nos processos de produção e nas relações de trabalho que culminaram na transformação da base técnica, inserindo um novo padrão de produção agrícola. Este se caracteriza pela intensificação das "relações agricultura/indústria, o aumento da produtividade e produção de alimentos além de alterações significativas nas relações sociais" (MAZZALI, 2000, p. 17).

A partir da intervenção estatal, baseada numa Política Agroindustrial (1960/70) que tinha por objetivo a integração da agropecuária no seu movimento a jusante com a indústria processadora, o CAI consolida-se, no espaço brasileiro, e passa a ser compreendido como processo de transformação de uma matéria-prima em diferentes produtos finais, sendo realizado através de integração técnica intersetorial entre indústrias, especialmente, de insumos agrícolas, e de produção agropecuária (SILVEIRA, 2005).

Ao atentar para um resgate teórico, pode-se apontar a década de 1950 como marco inicial para a emergência do CAI, enquanto uma ferramenta analítica. Naquela oportunidade, autores como J ohn Davis e Ruy Goldberg trazem o termo agribusiness para se referir à intensa transformação da agricultura norte americana, valorizando os vínculos intersetoriais existentes (SILVEIRA, 2005; MÜLLER, 1989).

Em 1973, Malassis propõe o conceito de sistema agroindustrial. Para este, o intuito era apreender as características do processo de industrialização da agricultura, onde o sistema agroindustrial seria constituído pelos seguintes segmentos:

\footnotetext{
1) o segmento de produção de insumos e serviços à montante da atividade agropecuária (crédito, assistência técnica, máquinas e equipamentos, insumos); 2) o segmento de produção agropecuária das matérias-primas; 3) o segmento de beneficiamento e de transformação industrial das matériasprimas a jusante da sua produção; 4) o segmento de comercialização e distribuição dos produtos finais (SILVEIRA, 2005, p. 218, apud, Graziano da Silva, 1996 e Batalha, 1996).
}

Composto por diferentes segmentos que amarram a produção intersetorial, o CAI também passa a ser compreendido de forma mais ampla, onde se passa a perceber a existência de complexos. Esta perspectiva tem permitido pôr em evidência a heterogeneidade, a qual ainda é traço marcante da agropecuária brasileira (RAMOS, 2007). A título de ilustração, tem-se, no espaço brasileiro, o CAI da soja, do leite, das aves, dos suínos, da cana-de-açúcar, dentre outros.

De fato, a agroindústria moderna não pode mais ser associada à fazenda, ela agora é constituída por capitais, como o financeiro, comercial e industrial (BELIK, 2007). Sendo assim, a transformação da matéria-prima em diferentes produtos finais é realizada pela indústria processadora, representante do capital agroindustrial, que promove a reestruturação do setor produtivo e transforma progressivamente os produtos agrícolas em matérias-primas (WILKINSON, 1986).

A relação intersetorial entre a agricultura, em especial, a familiar, e o(s) complexo(s) agroindustriais aponta para uma série de consequências. De imediato, observa-se a subordinação da agricultura à indústria representada numa diferenciação vertical, onde a primeira passa a depender duplamente da segunda: inicialmente, depende dos produtos industrializados para viabilizar a produção e alcançar altos níveis de produtividade, e, posteriormente, depende da indústria para a comercialização da sua produção. Esta subordinação também inclui outras facetas 
aparentemente invisíveis, como a monopolização do território pelo capital e/ ou a territorialização do capital nos espaços onde a monopolização do território pelo capital se expande, observando-se a inserção dos trabalhadores, não por meio da mercadoria trabalho, mas através da apropriação das mercadorias produzidas pelo trabalho (PAULINO, 2005). Já nos espaços onde predomina a territorialização do capital, a força de trabalho assume-se como mercadoria (OLIVEIRA, 1997).

No intuito de consolidar a expropriação da produção agrícola, as estratégias de desenvolvimento industrial adotadas foram justificadas pela "necessidade de 'modernizar' o campo, de superar as estruturas arcaicas e as limitações associadas à vida rural e aos camponeses, mediante o estímulo à penetração e difusão de empresas agrícolas capitalistas" (GUANZIROLI, 2001, p. 16).

Em paralelo, e também como fruto da subordinação da agricultura ao capital, observa-se um intenso processo de diferenciação horizontal marcado pela especialização produtiva, concentração de terras e de renda de algumas unidades de produção familiar, e, no reverso, a exclusão daquelas que não conseguem acompanhar o levante modernizante (e seletivo). Aos excluídos restaram duas opções: engrossar o levante rumo às cidades, na busca por emprego, ou resistir, utilizando redes informais de comercialização dos produtos excedentes destinados à subsistência.

A lógica que move o CAI, em sua racionalidade capitalista, é a possibilidade de obtenção do lucro, que é fruto da exploração do trabalho. Portanto, a possibilidade de extrair renda move a exploração capitalista da agricultura, uma vez que o capital ainda não encontrou meios para se apropriar totalmente da agricultura, através da industrialização. Ou seja, não superou os limites do tempo, do ciclo da natureza e dos riscos implícitos no processo de produção. Daí alguns dos fatores que garantiram a permanência e subordinação da produção familiar:

[...] a agroindústria, mais do que implicar uma subordinação real ao processo de trabalho agrícola, parece permitir a conservação da propriedade da terra em mãos do produtor direto por recusar-se a assumir a responsabilidade por um processo de trabalho ainda dominado pelas forças naturais (WILKINSON, 1986, p. 211).

Mas, deve-se atentar também aos fatores que levam os agricultores, em sua racionalidade, a manterem-se integrados ao CAI. Tomando essa perspectiva, é preciso observar a advertência levantada por Paulino (2005):

[...] é preciso deixar claro que quando se trata de analisar as estratégias que os camponeses adotam para se manter na terra, e a integração é uma delas, antes de mais nada é necessário romper com os parâmetros quase que mecânicos acerca de que se considera positivo no campo em termos de resultados econômicos, já que os rendimentos monetários auferidos com essa relação são, em geral, muito baixos (PAULINO, 2005, p. 03/4).

Paulino (2005) ${ }^{7}$ analisa os meandros que movem a indústria processadora e os camponeses $^{8}$ a manter os laços de dependência intersetorial. Segundo a autora, para

\footnotetext{
7 A autora analisa o sistema de integração no norte do Estado do Paraná/Brasil, região onde a integração camponeses-indústria ocorre principalmente nas atividades de avicultura de corte, sericicultura e fruticultura.
} 
os camponeses, as vantagens referem-se, principalmente, às possibilidades de um rendimento monetário em um ciclo mais curto que o das atividades tradicionais, o que lhes permite arcar com as despesas mensais, como: de utilização da forragem dos aviários (ou cama de frango), que é um adubo de excepcional qualidade, permitindo ao camponês economizar com a compra de insumos; de um mercado ávido por esse subproduto (cama de frango) da avicultura (o que pode representar um rendimento monetário extra, muitas vezes, superior à própria venda dos frangos à integradora). Estes aspectos fazem com que a integração seja um sonho acalentado por importante parcela dos camponeses mais pauperizados (PAULINO, 2005), no entanto os investimentos necessários ao ingresso na atividade inviabilizam a sua integração.

As tendências apontam para o aumento da especialização produtiva e a uma acentuada divisão territorial do trabalho. Esse processo pode ser observado, de forma clara, ao analisar a distribuição dos complexos agroindustriais no território brasileiro que é: estado de São Paulo, CAI cana-de-açúcar; Estado Paraná, CAI das aves e da cana-de-açúcar; Estado do Mato Grosso e Mato Grosso do Sul, CAI soja. Considerando o Estado do Rio Grande do Sul, percebe-se uma divisão territorial do trabalho ${ }^{9}$ entre os complexos do leite, do suíno, das aves e dos grãos.

A especialização produtiva tem apontado para outras consequências, dentre elas, seu contínuo caráter seletivo (já observado desde a emergência do CAI no Brasil). Mior (2005) analisa este processo:

[...] mudanças substanciais nos padrões de articulação agroindustrial, com repercussões restritivas sobre a continuidade de inserção da agricultura familiar. Patamares tecnológicos, especialização e escalas crescentes estão promovendo a seleção e a exclusão de produtores integrados das tradicionais cadeias produtivas de suínos, aves e leite, sobretudo no sul do Brasil (MIOR, 2005, p. 72).

Somam-se a isso as novas estratégias de atuação das empresas no mercado, decorrentes da nova dinâmica dos sistemas alimentares que privilegiam a adoção de modernas técnicas de produção, as quais são viabilizadas através da produção em escala, necessitando, para tanto, de investimentos elevados por parte dos agricultores, o que seleciona e limita os espaços de inserção de agricultores via integração das atividades aos complexos agroindustriais (MENEGUETTI, 2000).

\section{Contexto dos Complexos Agroindustriais no Estado do Rio Grande do Sul}

O complexo agroindustrial encontra-se amplamente difundido no Estado do Rio Grande do Sul. A distribuição espacial das atividades apresenta um comportamento no qual é possível delimitar uma divisão territorial do trabalho a partir de cada setor produtivo, o que induz, inevitavelmente, a uma especialização produtiva dos espaços.

\footnotetext{
${ }^{8}$ Na vertente teórica observada pela autora, expondo aqui de forma genérica, a agricultura camponesa é caracterizada pela força de trabalho familiar e a propriedade familiar da terra, onde, terra, trabalho e família conjugam-se como elementos essenciais.

${ }^{9}$ Este processo será explorado com mais perspicácia na próxima seção.
} 
Os principais produtos agropecuários que possuem vinculação direta com os complexos, no Rio Grande do Sul (RS), referem-se a aves, suínos, e à bovinocultura de leite. Na avicultura, destaca-se a produção de frangos e de ovos de galinha, sendo que as regiões da Serra e do Vale do Taquari podem ser consideradas como especializadas na produção de frangos de corte, respondendo por 54,7\% do efetivo de aves destinadas ao abate no cenário estadual (ATLAS, 2008). A suinocultura, por sua vez, destaca-se nas regiões Norte, Noroeste e Serra. Nessas regiões são realizadas a cria e a engorda dos animais, os quais são abatidos no próprio estado ou em Santa Catarina.

A produção de leite, por sua vez, que tem recebido atenção especial no Estado do Rio Grande do Sul, tende a continuar aumentando consideravelmente nos próximos anos. Para o ano de 2009, a perspectiva, em relação ao aumento da produção, foi de 8\%, comparada ao ano anterior. Atualmente, o Estado possui uma capacidade industrial instalada de cerca de 12,3 milhões de litros de leite/ dia, e a região Noroeste do Estado é responsável por 65\% da produção leiteira gaúcha. Acrescenta-se a esses dados, que o Estado é hoje o segundo maior produtor a nível nacional. Esses dados corroboram a importância que a atividade leiteira assume no Estado, bem como a tendência de aumento na produção a nível nacional (ATLAS, 2008).

Ao atentar à distribuição espacial da produção, no Estado, observa-se que a região Noroeste é responsável por $11,3 \%$ da produção estadual, seguida da região Celeiro com 11\%, Fronteira Noroeste com 9,4\% e Serra com 8,1\%. Esses dados deixam transparecer a divisão territorial do trabalho, fruto da necessidade de especialização produtiva dos espaços promovidos pela 'nova' dinâmica dos complexos. São remotos os casos onde as unidades de produção familiar conseguem conciliar duas atividades integradoras, se o fazem, acabam buscando outros interfúgios para suprimir a demanda por mão-de-obra.

Poder-se-ia explorar aqui uma série de fatores que contribuem para a produção de leite e seu destaque na porção Noroeste do RS, contudo, isto demandaria também uma análise mais acurada dos processos e fenômenos que vem norteando as racionalidades e a construção deste espaço. Assim, de forma direta, toma-se como hipótese o importante papel desempenhado pelas unidades de produção familiar ${ }^{10}$ frente à atividade leiteira. Porém, questiona-se como este estrato, que concentra a grande parte das propriedades rurais, com significativas dificuldades de reprodução socioeconômica, poderia ser responsável pela maior produção de leite do Estado?

Segundo Silva Neto e Basso (2005), o crescimento acentuado da produção leiteira, desde a década de 1980, na região denominada "colônias novas", deve-se em especial:

[...] a essa região sempre ter convivido com maiores dificuldades para a intensificação da sua agricultura. Com a eliminação do crédito subsidiado à produção de soja esta situação se agrava e os agricultores, principalmente os que dispõem de menores áreas, voltam-se para a produção leiteira que, além de possuir um bom potencial para a agregação de valor por unidade de área, é uma atividade que pode adaptar-se a diferentes situações ecológicas e socioeconômicas (SILVA NETO e BASSO, 2005, p. 59).

10 Frantz e Silva Neto (2005) concluíram que as regiões gaúchas onde é visível um processo de desenvolvimento rural mais dinâmico são aquelas nas quais existe uma significativa presença de unidades de produção familiar. 
Da mesma forma, cabe ainda recordar as contribuições de Paulino (2005) ao estudar o sistema de integração na avicultura, que descreve alguns elementos que tornam o uso da força de trabalho familiar tão interessante aos complexos:

[...] o trabalho é intenso e deve ocorrer ao longo de 24 horas do dia, ainda que no período noturno predominem as tarefas de vigilância, pois o trabalho mais pesado, como abastecimento dos comedouros e manutenção da 'cama de frango', que consiste no revolvimento sistemático da forragem para evitar a concentração de umidade ou de excrementos das aves, é feita ao longo do dia (PAULINO, 2005, p. 04).

Na racionalidade camponesa, o que importa não é a competitividade em uma produção isolada, mas sim garantir as condições para a reprodução social do grupo familiar. Sob esta lógica, os sistemas de produção leiteira, dada sua capacidade de adaptação a diferentes condições, dificilmente seguem os padrões tecnológicos recomendados pelas indústrias, principalmente, quanto ao rendimento e às escalas de produção (BASSO e SILVA NETO, 1999). Este comportamento não é observado somente entre os agricultores vinculados à produção leiteira, mas também no caso da avicultura e da suinocultura (PAULINO, 2005).

Os interfúgios e estratégias utilizadas pelos camponeses para garantir a manutenção de uma produção coerente com os interesses das empresas e, paralelamente, garantir a reprodução da unidade de produção familiar são, no mínimo, interessantes de considerar. Alguns deles podem ser pensados a partir do fato de que as unidades de produção familiar, apesar das exigências colocadas pelo sistema de integração, não se especializam exclusivamente na produção de leite, sendo a atividade associada a outras, e servindo de complemento à renda familiar. Ao estudar os produtores informais de leite no Estado do Paraná, Bem (2008) aponta que, no universo da reprodução camponesa, a bovinocultura de leite aparece como uma dentre outras atividades econômicas realizadas na propriedade pelo trabalho familiar.

No entanto, as tendências apontam para um aumento da especialização produtiva, e para a consequente exclusão daqueles que ainda resistem ou não conseguem 'consumir' os padrões tecnológicos exigidos pelas indústrias.

Até agora, centrou-se a atenção na caracterização e na análise dos elementos que contribuem para a manutenção, consolidação, e reprodução do sistema de integração indústria processadora versus agricultura familiar. Mas, àqueles camponeses excluídos, o que resta?

Aos excluídos do sistema de integração, cabe o êxodo rural, ou a resistência através de outras atividades (como o processamento de alimentos e/ ou bebidas), ou, ainda, a informalidade na produção de leite. Antes de deter a análise, no papel que o mercado informal vem exercendo sobre esse significativo contingente populacional, cabe frisar que o resgate de saberes e técnicas de processamento artesanal de alimentos, ou então, o processamento de bebidas, tem-se constituído como uma importante alternativa (SULZBACHER, 2007); mesmo frente aos processos de estrangulamento e pressão por parte do ambiente institucional que também vem atuando sobre esse setor.

A produção 'formal' de leite é normatizada a partir da portaria 56, de 1998, que regulamenta a produção de leite no território nacional. A formalização da produção de leite dos produtores do campo (camponeses, latifundiários e capitalistas), 
representa a integração com a indústria (lacticínio) e a informalidade refere-se à venda direta do produto in-natura ao consumidor (BEM, 2008). O caráter seletivo da indústria processadora, que exige a progressiva especialização dos produtores, exclui parte significativa de produtores que, no entanto, não representam significativo volume de produção, dada sua pequena escala de produção. Por este caráter, a comercialização informal de leite não chega a afetar a indústria processadora brasileira.

\section{A Realidade do Município de Roque Gonzales/RS}

O município de Roque Gonzales (Figura 01) soma, atualmente, uma população de 7.053 habitantes, sendo que, destes, aproximadamente, $65 \%$ residem no meio rural. Em relação à população total do município, o esvaziamento rural parece evidente ao se verificar que, em 1970, cerca de 10 mil habitantes estavam no espaço rural, já em 2000, houve queda para cerca de 5 mil. Cabe destacar, que houve também queda significativa na população absoluta do município, de 10 mil habitantes para, aproximadamente, 7 mil, no ano de 2000 (IBGE, 2000).

Figura 01 - Localização do município de Roque Gonzales no Estado do Rio Grande do Sul

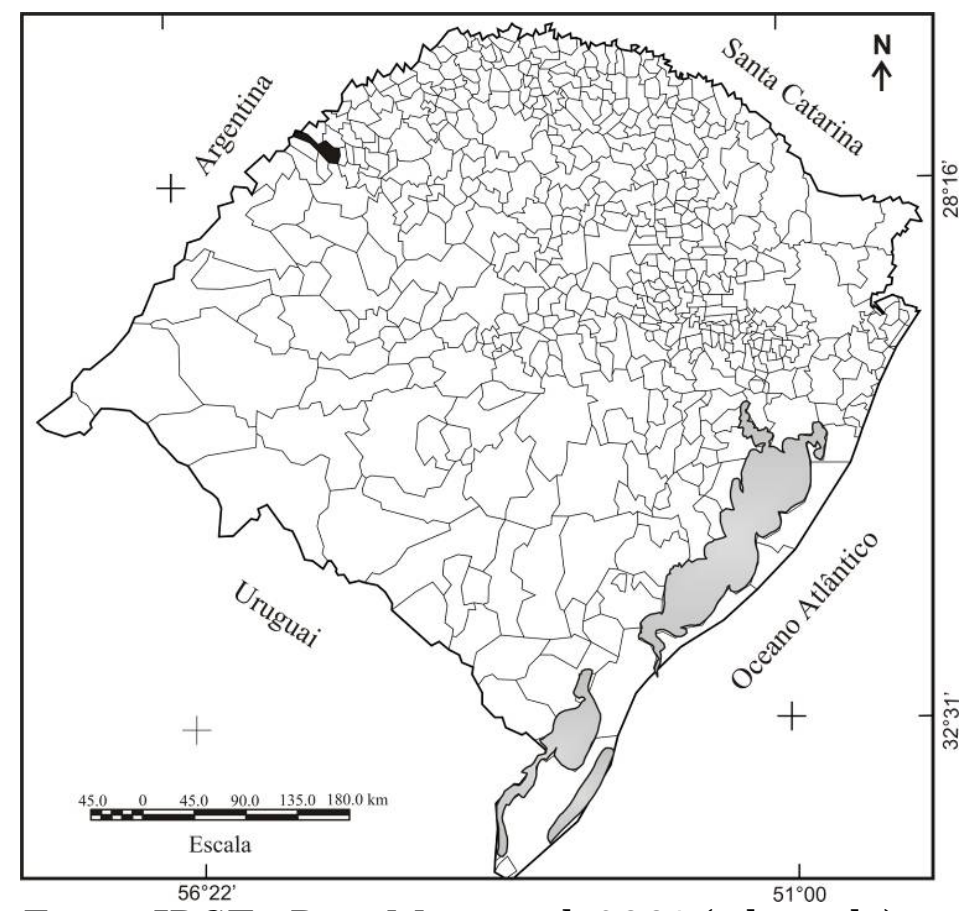

Fonte: IBGE - Base Municipal, 2001 (adaptado).

Essencialmente agrícola, as principais atividades do meio rural do município, historicamente, dizem respeito à cultura da soja, milho, cana-de-açúcar, suinocultura e a pecuária leiteira. Os dados secundários, ilustrados na tabela 01, relativos à evolução da área plantada com lavouras temporárias e vacas ordenhadas, revelam um processo de transição da matriz produtiva do município: 
Tabela 01 - Variações de área plantada de soja, milho, cana-de-açúcar e vacas ordenhadas no município de Roque Gonzales no período de 1990-2005

\begin{tabular}{c|c|c|c|c}
\hline \multirow{2}{*}{ Ano } & Soja & Milho & $\begin{array}{c}\text { Cana } \\
\text { Açúcar }\end{array}$ & Leite \\
\cline { 2 - 5 } & \multicolumn{3}{c|}{ Área Plantada (ha) } \\
\hline 1990 & 15.700 & 6.800 & 500 & Vacas Ordenhadas \\
1993 & 13.000 & 9.000 & 1.500 & 4.500 \\
1996 & 9.500 & 12.800 & 950 & 5.800 \\
1999 & 8.700 & 8.200 & 1.100 & 3.350 \\
2002 & 7.000 & 6.400 & 1.500 & 3.546 \\
2005 & 7.000 & 4.800 & 1.300 & 4.740 \\
2007 & 5.500 & 4.000 & 1.950 & 4.515 \\
\hline
\end{tabular}

Fonte: IBGE, 2008

Com predominância de pequenas unidades de produção, a estrutura fundiária do município de Roque Gonzales apresenta 91\% dos estabelecimentos com menos de 50 hectares, e esse mesmo percentual de estabelecimentos, ocupando apenas 55\% da área dos estabelecimentos do município. Em contrapartida, observa-se, a partir da tabela 02, que três estabelecimentos detêm a posse de $9 \%$ da área total dos estabelecimentos agropecuários. Essa fragmentação das terras, em grande parte, explica-se pelo histórico de colonização do município, que foi realizado predominantemente por colonos oriundos das antigas "colônias velhas".

Tabela 02 - Estrutura Fundiária de Roque Gonzales

\begin{tabular}{l|c|c|c|c}
\hline \multicolumn{1}{c}{ Área } & Estabelecimentos & $\%$ & Área total & $\%$ \\
\hline 0 a 10 ha & 786 & 43 & 3.094 & 10 \\
10 a 20 ha & 505 & 27 & 5.820 & 18 \\
20 50 ha & 380 & 21 & 8.762 & 27 \\
100 100 ha 500 ha & 109 & 6 & 4.411 & 14 \\
mais de 500 ha & 57 & 3 & 6.994 & 22 \\
\hline
\end{tabular}

Fonte: IBGE, Censo Agropecuário 1996

Em se tratando especificamente da atividade leiteira no município de Roque Gonzales, são encontradas seis empresas disputando a compra do leite produzido: Avipal/Elegê, Cooperbutiá, Bom Gosto, Alvorecer, Corlac, Pro-Milk. Destaca-se que nenhuma das empresas beneficia ou mesmo resfria o leite no município, sendo toda produção encaminhada para municípios vizinhos.

A produção leiteira do município, conforme tabela 03 , bem como o preço médio, o valor da produção, e percentagem que a atividade representa no Valor Agregado Bruto a preços básicos da agropecuária, apresentam um crescimento constante com exceção do ano de 1998, segundo dados obtidos junto à Fundação de Economia e Estatística do estado do Rio Grande do Sul. 
Tabela 03 - Produção e valores monetários da atividade leiteira em Roque Gonzales

\begin{tabular}{c|c|c|c|c|c}
\hline Ano & $\begin{array}{c}\text { Produção } \\
\text { (mil litros) }\end{array}$ & $\begin{array}{c}\text { Preço médio } \\
\text { litro }(\mathrm{R} \$)^{*}\end{array}$ & $\begin{array}{c}\text { Valor da } \\
\text { Produção } \\
(\mathrm{R} \$)\end{array}$ & $\begin{array}{c}\text { VAB a preços } \\
\text { Básicos } \\
\text { agropecuária }\end{array}$ & $\begin{array}{c}\text { \% em relação } \\
\text { ao VAB } \\
\text { Agropecuária }\end{array}$ \\
\hline 1996 & 6.531 & 0,21 & 1.372 & 15.933 & 8,6 \\
1998 & 6.886 & 0,21 & 1.446 & 22.595 & 6,4 \\
2000 & 8.012 & 0,27 & 2.163 & 22.375 & 9,6 \\
2002 & 7.891 & 0,27 & 2.131 & 17.826 & 11,9 \\
2004 & 6.781 & 0,42 & 2.848 & 21.339 & 13,4 \\
2006 & 7.675 & 0,46 & 3.607 & 24.995 & 14,4 \\
\hline
\end{tabular}

Fonte: FEE, 2008

Para complementação das informações da realidade do município de Roque Gonzales, realizou-se ainda aplicação de questionários semiestruturados a vinte e cinco produtores, distribuídos nas mais diversas regiões do município, apresentando diferentes níveis de eficácia técnica e gerencial. A escolha dos agricultores entrevistados deu-se por indicação dos principais agentes de desenvolvimento rural local (Secretária de Agricultura, Sindicato dos Trabalhadores Rurais, Emater/RS e Cooperativas), que apontaram para as diversas realidades encontradas no município.

Os resultados apontam que $48 \%$ dos entrevistados têm idade entre 31 e 40 anos, 36\% entre 41 e 50 anos, ou seja, a faixa de idade dos produtores de leite entrevistados é de 31 a 50 anos.

A escolaridade da maioria dos produtores entrevistados é bastante baixa, ou seja, $44 \%$ não possuem o ensino fundamental completo e apenas $8 \%$ tem ensino médio completo, sendo que não foram encontrados produtores com nível superior. As entrevistas revelaram ainda que, na área em estudo, $64 \%$ das unidades de produção ocupam três ou mais pessoas na atividade leiteira.

A atividade leiteira ocupa, nas unidades de produção, mais de $51 \%$ da área útil da propriedade. Recordando que o município é essencialmente composto por pequenas propriedades, esse fato pode indicar a intensidade da integração ou, até mesmo, a especialização produtiva de muitas delas.

Seguindo nessa linha, cerca de $60 \%$ dos entrevistados possuem até 10 animais em produção, ou seja, pequenas propriedades com pequena escala de produção e com certo grau de especialização produtiva (as raças das vacas também comprovam este dado, onde aparece com significativa frequência a raça Holandês11).

A ordenha encontrada nas propriedades ainda é predominantemente manual, enquanto que a mecânica responde por apenas $36 \%$ das unidades de produção. Já as formas de resfriamento da produção são a granel, em $12 \%$, e por imersão em $64 \%$ das unidades visitadas. Este é um dado de fundamental relevância, uma vez que, apesar de grande parte dos produtores entrevistados apresentarem certo grau de especialização produtiva, os mesmos não têm apresentado condições para investir em infra-estrutura tecnológica, a fim de "qualificar" a produção. Confrontando este fato com as tendências analisadas anteriormente, podemos identificar aqui um possível futuro contingente excluído do sistema, a menos, é claro, que as empresas revisem

\footnotetext{
${ }^{11}$ A raça Holandês é a mais indicada, tecnicamente, para a produção leiteira dada sua capacidade produtiva. No entanto, ela sofre com as intempéries climáticas e/ou condições agroecológicas, podendo afetar diretamente na produtividade.
} 
suas estratégias de exploração da força de trabalho familiar e passem a considerá-la mais importante do que as tecnologias ${ }^{12}$.

Fatos como a assistência técnica pública (Emater) incipiente e a preferência por produtores altamente especializados, por parte da assistência técnica privada (Avipal/ Elege), tornam a situação ainda mais vulnerável.

Na alimentação do rebanho leiteiro, destacam-se as pastagens. Entre as mais cultivadas para complementação da alimentação do plantel, destacam-se, no período de inverno, a aveia (100\%), o azevêm (76\%), a avica (8\%), trevo e ervilhaca, cada qual com 4\%. Já no período de verão, as principais pastagens cultivadas pelos entrevistados são: a aveia de verão (56\%), o sorgo (40\%), o tifton (12\%) e o milheto (12\%). Destaca-se que as pastagens perenes são pouco desenvolvidas, uma vez que $60 \%$ dos entrevistados afirmam não desenvolver as mesmas. Outro importante complemento na alimentação do rebanho é a silagem de milho (planta inteira), desenvolvida em $60 \%$ das unidades de produção visitadas. As rações e farelos são fornecidos em 32\% e 44\% respectivamente. Das unidades de produção visitadas, destaca-se também o alto fornecimento de sal mineral, sendo este da ordem de $60 \%$.

O processo de integração aos complexos agroindustriais no município, assim como no Estado, não é tão recente. Entre os agricultores entrevistados, cerca de $52 \%$ estão no sistema de integração leiteiro há pelo menos 10 anos. Além destes, outros fatos denunciam o alto grau de integração e a consequente especialização produtiva dos produtores familiares, como a produção própria das matrizes, a partir da inseminação artificial, em 56\% dos casos.

A título de ilustração, elegeu-se uma unidade de produção familiar representativa ${ }^{13}$, no que tange a esse cenário analisado, a fim de avaliar sua viabilidade econômica. A propriedade selecionada tem no leite sua principal atividade e fonte de renda, além de desenvolver atividades de subsistência. A área é própria e perfaz um total de 12 hectares. Destaca-se que 1,5 hectares são de mato nativo, sendo a superfície de área útil, da unidade de produção, de 10,5 hectares. As unidades de trabalho (UTh), exclusivamente familiar, são duas e estão diretamente envolvidas nas atividades da unidade de produção.

O rebanho é de 09 vacas em lactação, cuja produção média diária de cada uma é de 09 litros, acrescido de 5 vacas secas, 4 novilhas, e 5 terneiros. O preço médio de comercialização da produção, tomando por base o ano de 2008 , foi de $R \$ 0,50$ centavos/litro.

Os principais dados econômicos revelam que a Produção Bruta (PB) é de R\$ 16.079,25, o consumo intermediário (CI) de R\$ 6.179,15, a depreciação anual (DA) de R\$ 3.199,36, o nível de reprodução social (NRS) de R\$5.395,00 e a renda agrícola é de R\$ 6.264,74. Nesse sentido, percebe-se no gráfico 1, que o NRS14 não foi atingido. Dessa forma, a unidade de produção não se viabilizaria economicamente.

\footnotetext{
12 Fato que, diga-se de passagem, não seria surpreendente se ocorresse.

13 A opção pela apresentação de um único caso ocorre por não ser objetivo deste trabalho a análise detalhada do contexto de cada Unidade de Produção, no entanto, em BOLTER (2009) é possível a análise das demais 24 unidades de produção, inicialmente investigadas. Destaca-se ainda que a Unidade de Produção aqui apresentada é a que representa a realidade da maioria das unidades estudadas.

14 Valor correspondente a 13 salários mínimos por ano/UTf, ou seja valor que possivelmente seria pago ao trabalhador envolvido na atividade se esse fosse prestar serviços fora da propriedade.
} 
Gráfico 01 - Realidade encontrada

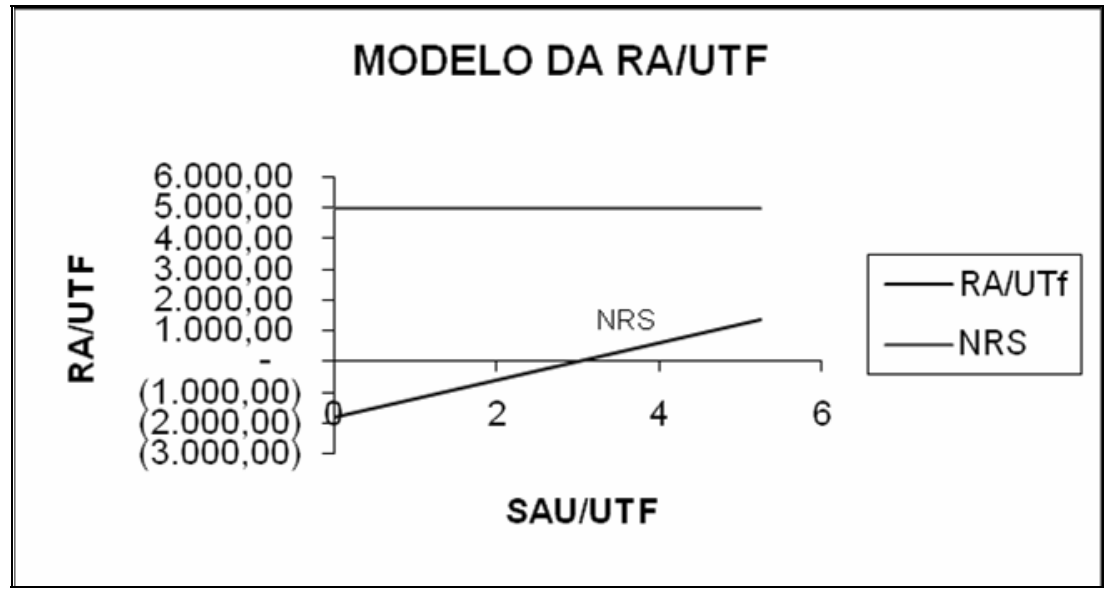

Fonte: Resultados da Pesquisa

Realizando uma simulação de que essa propriedade, mantendo as mesmas características, viesse a agroindustrializar sua produção, transformando-a em queijo, e, assim, adquirindo um preço médio de $\mathrm{R} \$ 0,9015$ pelo litro de leite produzido, a situação apresentada, no gráfico 02, mostra a mudança de realidade. Nesse novo cenário, destaca-se o alcance do Nível de Reprodução Social.

Gráfico 02 - Realidade Simulada

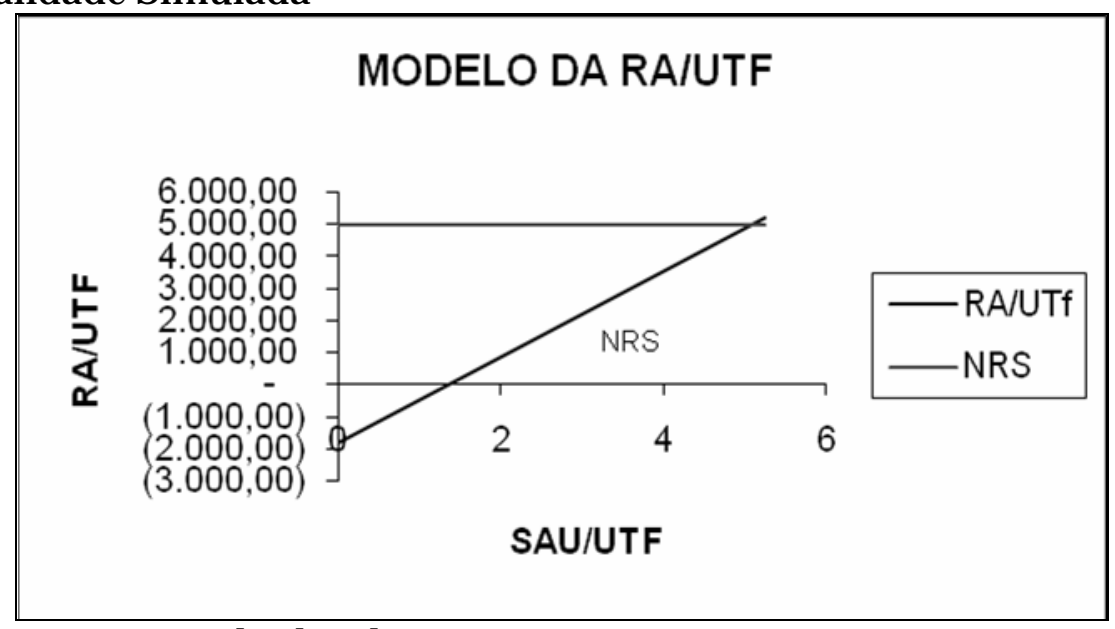

Fonte: Resultados da Pesquisa

Por fim, percebe-se que podem existir espaços de fuga da aparente acomodação no sistema de integração que, além de usar intensivamente a força de trabalho familiar, vem exigindo a constante adoção de novas tecnologias, a fim de ampliar escala e qualidade da produção. Além disso, o mercado consumidor atual do município de Roque Gonzales, por exemplo, de leite e seus derivados, é praticamente todo abastecido por produtos oriundos de outros municípios (BOLTER, 2009).

A acomodação expressada pela garantia de uma renda mensal relativamente fixa poderia, então, ser canalizada para outra atividade, como o beneficiamento de leite na própria unidade de produção. Isto demandaria, porém, alguns custos iniciais,

15 Tomando-se por base que o preço médio do quilo de queijo na cidade do estudo, no ano de 2008, foi de $\mathrm{R} \$ 9,00$ e que se usa uma média de 10 litros de leite para a confeç̧ão de $1 \mathrm{~kg}$ de queijo. 
que não necessariamente seriam a instalação completa de uma agroindústria, mas sim, adaptações de instalações e equipamentos já existentes na unidade de produção, para início das atividades. Além do mais, observa-se que muitas unidades de produção familiar estão em constantes investimentos (instalação de pastagens, troca ou concerto de equipamentos como resfriador e ordenhadeira mecânica), a fim de garantir a manutenção da integração. Sendo que estes recursos, que no ano somam em média um total de $\mathrm{R} \$ 1.500,00$, segundo Bolter (2009), poderiam ser revertidos para uma atividade que, no mínimo, propiciasse a autonomia da propriedade.

Esses espaços de fuga, aqui explorados de forma genérica, no entanto, não podem ser colocados como exclusivos para o universo em questão. Trata-se, antes de tudo, de uma revisão urgente da relação do produtor com a produção e comercialização. Ou até mesmo, uma revisão da matriz produtiva, que vem subordinando os produtores familiares às indústrias integradoras. Neste caso, necessita-se de uma avaliação visando ao como, por que, e para que produzir.

Por fim, trata-se dos agentes de ATER e atores sociais locais e regionais passarem a observar a realidade com um olhar mais apurado para as necessidades locais e não, exclusivamente, para os interesses do capital industrial. A revisão da ação desses agentes poderia ser um passo inicial, inclusive na disputa por recursos financeiros nas esferas estaduais e federal, incentivando os produtores familiares a trilharem seus caminhos de forma autônoma.

\section{Considerações Finais}

Dentre os resultados alcançados no trabalho, pode-se destacar uma dualidade inicial: por um lado, que a integração com o complexo agroindustrial garante a manutenção da unidade de produção familiar, mas não sua expansão em longo prazo (não contabiliza os custos de depreciação, por exemplo); e, por outro lado, ao manter uma renda fixa, não estimula a busca por alternativas diferenciadas capazes de promover autonomia em relação ao sistema, dado que esta busca implica diretamente em submeter-se a riscos, que podem ser econômicos, sociais e ambientais.

No reverso da questão, o CAI também promove a diferenciação horizontal das unidades produtivas com a exclusão daquelas que não estão dentro dos padrões 'tecnológicos' exigidos. Estas enfrentam uma série de problemas para buscar outras estratégias, uma vez que a produção leiteira é regionalmente difundida, fato que deixa outras atividades como pano de fundo, não recebendo a devida atenção por parte, principalmente, das instituições ou agentes de extensão públicos.

No caso específico de Roque Gonzales, mais de 50\% das unidades de produção familiar do município produzem e comercializam leite in natura para as indústrias processadoras ou para intermediários, este universo se apresenta com significativo potencial para a criação de estratégias voltadas para o beneficiamento do produto. No entanto, mesmo frente a esta realidade, a consolidação de alternativas como um Sistema Agroalimentar Localizado se demonstra inviável, em curto prazo, dada às dificuldades para a mobilização dos recursos passivos no território, fruto de um processo histórico de influência do CAI e de estímulo ao trabalho individual.

Ao finalizar, sem, contudo, ter a pretensão de concluir, propõe-se algumas reflexões. Afinal, frente ao contexto colocado no município em estudo, seria viável e de interesse dos produtores sair da possível acomodação e tomar iniciativas como o beneficiamento do leite produzido (seja individual ou no coletivo) com as condições técnicas disponíveis? 
Além disso, levando em conta que, a integração ao complexo agroindustrial do leite é uma estratégia colocada, principalmente, nas ações das políticas regionais, quais seriam as possibilidades que poderiam ser incentivadas, a fim de promover uma revisão desta conjuntura e a adoção de outros modelos que conseguissem aproveitar a infraestrutura e a tecnologia disponíveis?

A ação dos agentes de extensão rural se coloca conflituosa: de um lado uma estratégia amplamente difundida e formalmente aceita na região (complexo agroindustrial do leite), e no outro extremo, a aparente acomodação dos produtores familiares que não visualizam alternativas que lhes possam ser mais rentáveis. Sob esta ótica, e, a partir dos dados levantados, percebe-se que o modelo de desenvolvimento regional vem conduzindo ao aumento progressivo da especialização produtiva deste espaço, e à consequente exclusão ou até proletarização rural daqueles que não conseguem se enquadrar nos parâmetros mínimos postos pelo modelo. Será que é necessário a sociedade vivenciar novamente as consequências da adoção de estratégias únicas de desenvolvimento para que assim possa repensar os caminhos?

\section{Referências}

ATLAS Socioeconômico do Rio Grande do Sul. Disponível em: http:// www.scp.rs. gov.br/ ATLAS. Acesso em 29 de novembro de 2008.

BELIK, Walter. Agroindústria e política agroindustrial no Brasil. In.: RAMOS, Pedro et al. Dimensões do agronegócio brasileiro: políticas, instituições e perspectivas. Brasília: MDA, 2007. p. 18-52.

BEM, A. Os produtores informais de leite: o lugar da reprodução camponesa no debate teórico da questão agrária. Cascavel/ PR: Coluna do Saber, 2008.

BOLTER J . A. G. Dinâmica Agrária e a Produção Leiteira: Um Estudo no município de Roque Gonzales - RS. Dissertação (Mestrado em Desenvolvimento) - Universidade do Noroeste do Rio Grande do Sul - Unijui, Ijui, 2009.

BOUCHER, F. Desarrollo rural, acciones colectivas y concentraciones agroempresariales. In.: XII J ornada Hemisférica de PRODAR y III Encuentro Nacional de Agroindústria Rural de Guatemala, 2000.

DUFUMIER, M. Projetos de Desenvolvimento Agrícola: manual para especialistas. Tradução Vitor de Athayde Couto. Salvador: EDUFBA, 2007.

FUNDAÇÃO de Economia e Estatística - FEE. FEE Dados. 2000. Disponível em http:// www.fee.rs.gov.br/ feedados/consulta/sel_modulo_pesquisa.asp. Acesso em 05 de dezembro de 2008.

GALBRAITH, J . K. A Natureza da Pobreza das Massas. Nova Fronteira. 1979.

GÓMEZ, C. A. C.; BOUCHER, F.; REQUIER-DESJ ARDINS, D. ¿Cómo <<activar>> los sistemas agroalimentarios localizado en América Latina? Un análisis comparativo. In.: Revista Agroalimentaria, no 22, enero-junio, 2006. p. 17-27. 
GOVERNO do Estado do Rio Grande do Sul. Secretaria da Coordenação e Planejamento. Rumos 2015 - Estudo sobre desenvolvimento regional e logística de transportes no RS. Porto Alegre, 2005.

GUANZIROLI, C. E. et al. Agricultura familiar e reforma agrária no século XXI. Rio de J aneiro: Garamond, 2001.

INTITUTO Brasileiro de Economia e Estatística - IBGE. Banco de Dados Agregados. 2000. Disponível em: http://www.sidra.ibge.gov.br/, acesso em 19 de janeiro de 2009.

HAAS, J . As Diferenciações Transformações Sócio-Territoriais no Espaço Agrário das Missões/ RS. 2008. Dissertação (Mestrado em Extensão Rural) Universidade Federal de Santa Maria, Santa Maria, 2008.

MAZZALI, L. O processo recente de reorganização agroindustrial: do complexo à organização “em rede”. São Paulo: Ed. UNESP, 2000.

MENGUETTI, G. A. Dinâmica e espaços de mercado na cadeia de suínos da produção independente aos contratos de integração - as pequenas indústrias formais e informais como estratégia de inserção nos mercados. Dissertação de Mestrado (Mestrado em Desenvolvimento, Agricultura e Sociedade), Universidade Federal Rural do Rio de Janeiro, 2000.

MIOR, L. C. Agricultores familiares, agroindústrias e redes de desenvolvimento rural. Chapecó: Argos, 2005.

MONTENEGRO GÓMEZ, J. R. Desenvolvimento Territorial Rural. Mudar Para Que Nada Mude. In: 1ำ Encontro da Rede de Estudos Rurais. Anais... Niterói/ RJ : NEAD, 2006.

MÜlLER, G. Complexo Agroindustrial e modernização agrária. São Paulo: Hucitec: EDUC, 1989.

OLIVEIRA, A. U. de. Agricultura Camponesa no Brasil. 3 ed. São Paulo: Contexto, 1997.

Geografia e território: desenvolvimento e contradições na agricultura. In.: Boletim de Geografia Teorética. Rio Claro, v. 25, n. 49-50, 1995 . p. 15-58

PAULINO, E. T. Camponeses e indústrias: aspectos da integração no norte do Paraná. In: III Simpósio Nacional de Geografia Agrária, II Simpósio Internacional de Geografia Agrária...Anais... Presidente Prudente: UNESP, 2005.

- Frações capitalistas e frações camponesas do território: por uma distinção geográfica. In.: XIV Encontro Nacional de Geógrafos. Anais... Rio Branco: AGB, 2006. p. 01-12.

RAMOS, P. Referencial teórico e analítico sobre a agropecuária brasileira. In.: RAMOS, Pedro et al. Dimensões do agronegócio brasileiro: políticas, instituições e perspectivas. Brasília: MDA, 2007. p. 18-52. 
REQUIER-DESJ ARDINS, D. Agro-industria rural y sistemas agroalimentares localizados: ?Cuáles puestas?. In.: X Aniversário de PRODAR, Anais... Quito, 1999. Disponível em: http: www.prodar.org/cd.htm, acesso em 10 ago. 2007.

SILVA NETO, B. e BASSO, D. A Produção de leite como Estratégia de Desenvolvimento para o Rio Grande do Sul. In.: Revista Desenvolvimento em Questão, Vol. 5, p. 53-72, Ijuí: Ed. Unijuí, 2005.

SILVEIRA, R. L. L. Complexos Agroindustriais, Redes e território. In: SILVEIRA, R. L. L. e DIAS, L. C. (org.) Redes, Sociedades e território. Santa Cruz do Sul: EDUNISC, 2005, v1, p. 215-255.

SULZBACHER, A. W. A agroindústria familiar rural enquanto alternativa para agricultura familiar: estudo de caso no município de Chapada/RS. Monografia (Curso de Geografia - Licenciatura Plena) Universidade Federal de Santa Maria, Santa Maria, 2007.

SULZBACHER, A. W. e DAVID, C. de. Alternativas para o Espaço Rural: importância de compatibilizar políticas públicas com saberes locais. In.: Campo-Território: Revista de Geografia Agrária. v.3, p.14 - 37, 2008.

TESTA, V.M., NADAL, R., MIOR, L.C., et al. O desenvolvimento sustentável do Oeste Catarinense: proposta para discussão. Florianópolis: EPAGRI, 1996. 247p.

WILKINSON, J. Distintos enfoques e debates sobre a produção familiar no meio rural. In: Agroecologia e desenvolvimento rural sustentável, Porto Alegre. V $1, \mathrm{n} 3$, jul/ set, 2000.

. Mercosul e produção familiar: abordagens teóricas e estratégias alternativas. In: Estudos Sociedade e Agricultura, n 8, abr. 1997, p. 25-50.

O estado, a agroindústria e a pequena produção. São Paulo: HÜCITEC-CEPA/BA, 1986. 